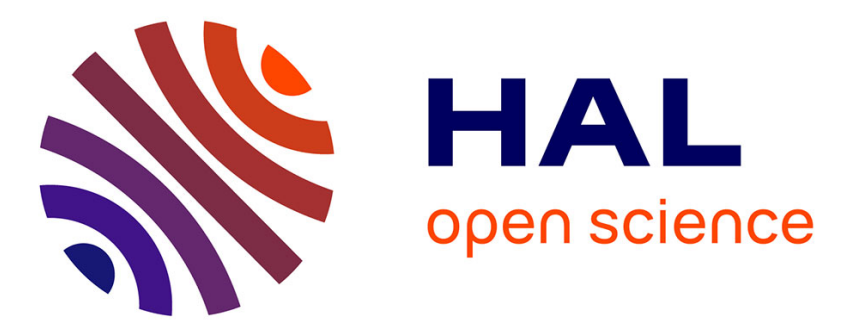

\title{
Culture and Achievement Motivation in Sport: A Qualitative Comparative Study Between Maghrebian and European French Adolescents
}

Paul Fontayne, Philippe Sarrazin, Jean-Pierre Famose

\section{- To cite this version:}

Paul Fontayne, Philippe Sarrazin, Jean-Pierre Famose. Culture and Achievement Motivation in Sport: A Qualitative Comparative Study Between Maghrebian and European French Adolescents. European Journal of Sport Science, 2001, 1 (4), pp.Available at. 10.1080/17461390100071403 . hal-00387232

\section{HAL Id: hal-00387232 \\ https://hal.science/hal-00387232}

Submitted on 25 May 2009

HAL is a multi-disciplinary open access archive for the deposit and dissemination of scientific research documents, whether they are published or not. The documents may come from teaching and research institutions in France or abroad, or from public or private research centers.
L'archive ouverte pluridisciplinaire HAL, est destinée au dépôt et à la diffusion de documents scientifiques de niveau recherche, publiés ou non, émanant des établissements d'enseignement et de recherche français ou étrangers, des laboratoires publics ou privés. 
European Journal of Sport Science, vol. 1, issue 4

(C)2001 by Human Kinetics Publishers and the European College of Sport Science

\title{
Culture and Achievement Motivation in Sport: A Qualitative Comparative Study Between Maghrebian and European French Adolescents
}

\author{
Paul Fontayne, Philippe Sarrazin, and Jean-Pierre Famose
}

Within the framework of achievement motivation, the authors assessed gender and ethnic differences for preferential choices of social situations of achievement (e.g., academic, sport, art) and motivational goals pursued. A contents analysis of the essays of 202 pupils (boys and girls of Maghrebian and European origin) from a suburb of Paris was used. The subjects of Maghrebian origin tended to choose the school for social situations of achievement, while those of European origin appreciated the possibility for sport and art. Gender differences were more specifically pronounced for the Maghrebian girls. Concerning motivational goals, boys showed a less-marked orientation towards mastery goals than girls, whatever the social situation of achievement. Finally, the data analysis revealed that the nature of the social domain of achievement influences whether adolescents become intrinsically or extrinsically motivated.

Key Words: achievement motivation, culture, goals, social situation, gender

\section{Key Points:}

- During the last 20 years, studies on motivation in sport or academic domains has adopted a social-cognitive approach in which achievement goal theory became one of the most important approaches.

- Limiting the study of motivation to the study of mastery versus social comparison is reductionistic when persons from minority cultural groups are concerned.

- People, and particularly adolescents, may hold multiple goals, each of which may influence their level of motivation for a particular social domain.

\section{Introduction}

During the last 20 years, studies on motivation in sport or academia have adopted a socialcognitive approach. One approach, achievement goal theory, became one of the most important approaches to understanding sport motivation. Goals are cognitive representations of the different purposes people may have in achievement situations, and are presumed to guide behavior and cognition, and affect academic, work, or sport situations (13). In this approach, goals drive decision making and behavior of individuals in the context of achievement. Thus, to understand motivation, it is necessary to understand the meaning/purposes of behavior in a variety of contexts.

Although multiple goals influence behavior $(23,33)$, two goals have received considerable attention from researchers: mastery goals (also called task oriented) and social comparison goals 
(also called ego oriented). Central to a mastery goal is the belief that effort leads to success, and the focus of attention is on the intrinsic value of progress. With a mastery goal, individuals are oriented toward developing new skills, trying to understand their practice, improving their level of competence, or achieving a sense of mastery. In contrast, central to a social comparison goal is a focus on one's ability and sense of self-worth. Ability is shown by doing better than the others, by surpassing the norm, or by achieving success with little effort. Consequently, selfworth is determined by one's perception of ability to perform and to compete successfully (see 29, for review in French).

Such an approach has recently been criticized by several authors. Indeed, the focus on these two goal structures precludes the generation of information regarding potentially more salient goals. The fact that evidence has shown that cultural groups within many social domains (e.g., school, sport) appear to be motivated in different ways has interested researchers for many years (e.g., 8, 9). Moreover, Maehr $(21,22,24)$ has suggested that motivational theories have primarily referred to the dominant view of white male Americans. In contrast, Maehr and Nicholls (24) proposed a conception of achievement motivation that takes into account socio-cultural variations in the purposes of achievement and preferential means to reach these goals. For Maehr (22), and Maehr and Braskamp (23), motivated behavior is determined by the pursuit of multiple goals (i.e., personal incentives), based on what a person defines as "success" and "failure" in a particular situation.

Maehr (22) proposed four broad categories of achievement goals: (a) mastery (or task) goals (such as working to improve yourself, to understand something, to experience novelty), (b) social comparison (or ego) goals (such as doing better than the others), (c) social solidarity goals (such as pleasing others, making others happy), and (d) extrinsic rewards goals (such as working for recognition, or a reward of some kind). Therefore, to limit research to mastery versus social comparison goals is reductionistic, especially when people from minority cultural groups are concerned. Such an approach fails to consider adequately other relevant and interacting goals (8, 9, 31). School and sport does not only consist of studying academic material or sport skills within a mastery or performance framework. People, and particularly adolescents, may hold multiple goals, each of which may impact upon their level of motivation for a particular task. These multiple goals may interact, resulting in a complex framework of motivational determination of activities, strength of action, and persistence of engagement.

The research reported here therefore raises the following questions: (a) Which social situation of achievement is most important according to the ethnic origin and gender of the person? and (b) Which preferential goals of achievement do individuals pursue according to their ethnic origin, gender, and to the social situation of achievement?

From our point of view, to ask these questions, the comparison of two groups of adolescents, from French Maghrebian and European cultures, should be very fertile. Maghrebian countries (e.g., Tunisia, Morocco, and Algeria) are former French colonies and comparisons between French Maghrebians and European French adolescents is a comparison between typical nonWestern and Western societal values. Concerning the choice of achievement situations, research (e.g., 3, 6) shows that the immigrated population of French Maghrebians inherit from their culture a strong appreciation of education because it promotes better social status. Therefore, we 
expected to see Maghrebian adolescents reporting more academic situations of achievement than their European counterparts. Furthermore, anthropological and sociological studies (see 4) have characterized traditional Maghrebian societies as group-oriented cultures, so we expected to find Maghrebian adolescents, compared to European adolescents, to be more oriented toward collectivist motives and less toward individualistic motives (30). In addition, according to several authors (for reviews, see 15, 16), girls stay longer and succeed better at school than boys. In France, for every 100 girls and 100 boys entering secondary school, 40 girls and 28 boys reach the final year of school (Data of the Ministry of National Education, 1997). Moreover, girls are perceived by their teachers as more "serious" and more interested in schoolwork than boys (1416). For the Maghrebian girls, education is perhaps even more important than it is for European girls because school achievement represent an opportunity to resist the traditional patriarchal system typical of Maghrebians; success at school allows emancipation (4, 20). Finally, in most studies of goal orientations, girls and women are found to be less extrinsically oriented or more intrinsically oriented than boys and men $(10,11,17,19,21,24)$. Moreover, it appears this can be generalized to different social activities (particularly sport and academic domains; 12, 13). Consequently, our hypotheses for this study were:

1. Cultural and gender differences in choices of preferential social domain of achievement should appear. Maghrebian adolescents should choose academic situations more than the European adolescents; similarly girls should choose academic situations more than the boys.

2. The goals pursued by the adolescents of the two ethnic groups should be different. (a) The Maghrebian adolescents, compared to European adolescents, should be less oriented towards ego and extrinsic rewards goals and more oriented toward mastery and social solidarity goals. (b) The girls, compared to the boys, should be less oriented toward ego and extrinsic reward goals and more oriented toward mastery and social solidarity goals. 3. The goals pursued by the adolescents of the two groups will depend upon the social situation of achievement.

\section{Method}

To test our hypotheses, we chose a qualitative method: the content analysis. This choice was made for methodological and theoretical reasons. First, most of the studies attempting to evaluate achievement goal orientations have used questionnaires. The great majority of these questionnaires are principally focused on the measure of mastery and social comparison goal orientations. They omit evaluation of social solidarity and reward goal orientations (see 29). Even if some questionnaires exist (e.g., Inventory of School Motivation, 25; Motives Questionnaire, 28), none of them are validated in the French language. Second, the recent discussion about the bipolarity or the orthogonality of achievement goals (see 29) suggests that such an approach actually fails to adequately investigate the interaction between multiple goals in cross-cultural studies. Consequently, it seems necessary to adopt a more qualitative approach to study situational, cultural, and individual determinants of achievement goals. ${ }^{1}$

\section{Subjects}

Our sample was composed of 202 pupils (107 girls and 95 boys) of eight secondary schools from a suburb of Paris, France. The adolescents were between 13 and 18 years old $(M=15.46, S D=$ 0.78). More precisely, two populations comprised this sample: (a) 142 Europeans (71 girls and 
71 boys), aged 15.28 years old $(S D=0.70)$; and (b) 60 Maghrebians (36 girls and 24 boys), aged 15.88 years old $(S D=0.78)$.

\section{Material}

The content analysis was realized from pupil compositions, written during the French test of the "Brevet des Collèges" 2 of the district of Versailles (10 km west of Paris). The instructions were, in part:

Discuss one of the following two topics:

Topic 1 (imagination): You lived a day of success or of memorable failure (during school exercises, sport, or other tests). Give the detailed story clarifying your feelings. ${ }^{3}$

\section{Instrument}

There exists several methods of content analysis (see 1,27). The method used here was one of the "logico-semantics" methods defined by Mucchielli (26). In this approach, contents analysis organizes the raw data into interpretable and meaningful themes and categories employing either deductive or inductive procedures. The deductive approach involves using a predetermined set of themes and categories to organize the quotes, while the inductive approach allows the themes and categories to emerge from the quotes. For this study, we used both methods. Inductive analysis was employed to identify the major emergent themes and categories from the data (Table 1). Each category is a sort of "common denominator" to which can be linked a set of statements without forcing meaning. Deductive analysis was utilized to classify and select the quotes that refer to goal achievement. For this classification, we used the four categories of goals defined by Maehr (22).

Table 1 Synoptic Table of the Categories of Coding Used During the Contents Analysis

\begin{tabular}{|c|c|c|}
\hline Category & Title & Domain of definition \\
\hline 1 & Definitions & $\begin{array}{l}\text { The quotes that define success or failure for the concerned individuals are } \\
\text { arranged in this set. They define success or failure in terms of: } \\
\text { a. antecedents: the causes of the success or failure and the personal } \\
\text { characteristics of the individuals judged as desirable and undesirable. For } \\
\text { example: "to have ability, to be lazy, to have a good personality, to be tall . . .." } \\
\text { b. behaviors: actions directly linked to success/failure by the subject. } \\
\text { c. consequences: result of an individual's behavior or personal characteristics. In } \\
\text { this category, the quotes are arranged either as a material result (e.g., grades, } \\
\text { money, sport victories, good notes, access to a superior academic level), a } \\
\text { symbolic result (e.g., sport title, success, failure, celebrity, respect), or a social } \\
\text { consequence (e.g., social [dis]approbation, encouragement, reprimands). }\end{array}$ \\
\hline 2 & Affects & $\begin{array}{l}\text { The affective consequences of success/failure. } \\
\text { a. positive emotions: for example, enjoyment, pride, happiness. } \\
\text { b. negative emotions: for example, shame, disappointment, frustration. }\end{array}$ \\
\hline 3 & $\begin{array}{l}\text { Social situations of } \\
\text { achievement }\end{array}$ & $\begin{array}{l}\text { This last domain generally referred to art activities (e.g., music, theatre) and } \\
\text { leisure activities (e.g., video games). }\end{array}$ \\
\hline 4 & Goals of achievement & $\begin{array}{l}\text { The four goals of achievement defined by Maehr (1984): mastery, social } \\
\text { comparison, social solidarity, and reward. }\end{array}$ \\
\hline 5 & Context & $\begin{array}{l}\text { The place, the time, or the action which took place. There was no direct report of } \\
\text { success/failure. }\end{array}$ \\
\hline 6 & Social function & The social functions of the domain of achievement. \\
\hline
\end{tabular}




\section{Validity of the Analysis}

To further limit the potential of analyst bias, we used the following procedure. Each essay of the adolescents was randomly assigned to each of the three authors of this paper. Each researcher independently analyzed all data and realized the content analysis in two ways. First, after we became highly familiar with the essays (e.g., this procedure is called "floating reading"; 1), we created an inventory of statements, using keywords, names and associated adjectives, or paraphrases. We classified them as "contents." These statements or units of coding were then regrouped in "subjects," then in "subcategories," and finally into categories, or "units of numeration" (26), or even "units of recording" (1). These units, which varied in length from a word, to a paragraph, comprised the raw data for the content analysis. After a meeting where we decided on a common grid of analysis (Table 1), the essays were reassigned to a second researcher to test the homogeneity of the grid. To complete this operation, all the essays were recoded by the second researcher from the indications (social situation and achievement goals) which were going to be used to compare the two studied populations. From these results we calculated an index of coherence " $\mathrm{N}$ "4 (18) between the two successive analyses. For this analysis, the index of coherence is .87 . We considered the homogeneity of the coding as acceptable.

\section{Hypothesis 1}

\section{Results}

To answer the first theoretical question about the choice of the social situation of achievement (SSAch), we executed a series of chi-square tests. First, a one variable chi-square test revealed that the choice between the different SSAch (sport, academic, and other domain; see Table 1) was not equal: $\chi^{2}(2, N=202)=42.94(p<.0001)$. The analysis of the a posteriori cells' contribution ( $p<.01$; adjusted residuals calculation) revealed an over-representation of sport situations of achievement and an under-representation of other domain situations of achievement. Second, two new chi-square tests were conducted with gender and ethnic origin (Maghrebian vs. European) as the independent variable and the SSAch as the dependent variable ${ }^{5}$. For the gender variable, the results were non-significant: $\chi^{2}(2, N=202)=4.42(p=.11)$. For the ethnic origin variable, the results showed a significant difference: $\chi^{2}(2, N=202)=14.31(p=.0008$; see Table 2). The analysis of the a posteriori cells' contribution $(p<.01)$ revealed an overrepresentation of Maghrebian adolescents and an under-representation of European adolescent profiles among the academic situations of achievement, and the opposite among the other domain situations of achievement. There was no significant difference concerning sport situations of achievement (see Table 2).

Table 2 Distribution of the Choice of the Social Situations of Achievement According by Gender and Ethnic Origin of the Subjects

\begin{tabular}{|c|c|c|c|c|c|}
\hline \multirow{2}{*}{ Social situation } & \multicolumn{2}{|c|}{ European origin } & \multicolumn{2}{c|}{ Maghrebian origin } & \multirow{2}{*}{ Total } \\
\cline { 2 - 6 } & Boys & Girls & Boys & Girls & \\
\hline Academic & 16 & 21 & 9 & 20 & 66 \\
\hline Sport & 39 & 38 & 13 & 16 & 106 \\
\hline Other domains & 16 & 12 & 2 & 0 & 30 \\
\hline Total & 71 & 71 & 24 & 36 & 202 \\
\hline
\end{tabular}




\section{Hypotheses 2 and 3}

Before answering the second theoretical question of our study, concerning the preferential goals of achievement, we proceeded to a double standardization of our data. Indeed, the length of each essay differed from one individual to another, and the sizes of the two ethnic groups were unequal. So, after having counted the number of quotes relative to each category of goals (i.e., mastery, social comparison, social solidarity, and reward), we conducted: (a) one standardization per subject over all items to rule out individual differences in response length, and (b) one standardization per category of goals over all subjects to rule out the differences in group means $(2,28)$.

In a second stage, in response to our hypotheses (H2 and H3), a general MANOVA procedure was conducted, with DV as standardized scores for each goal, and IV for gender (male vs. female), ethnic origin (Maghrebian vs. European), and social situation of achievement ${ }^{6}$ (sport vs. academic).

Results of the MANOVAs revealed no main effects. A significant Gender $\times$ Goals interaction effect was found: Wilks's Lambda $(3,162)=.95(p=.03)$. A significant Social Situation $\times$ Goals interaction was also found: Wilks's Lambda $(3,162)=.63(p<.0001)$. The only effect involving ethnic origin near significance was an Ethnic Origin $\times$ Social Situation $\times$ Goals interaction effect: Wilks's Lambda $(3,162)=.95(p=.08)$.

Concerning the gender variable, the univariate tests revealed a significant effect for the mastery goal $\left(F_{1,170}=6.49, p=.01\right)$; the boys $\left(M_{\mathrm{z} \text { scores }}=-.22\right)$ obtain a lower score on this goal than the girls $\left(M_{\mathrm{z} \text { scores }}=.17\right)$. For the variable social situation, the univariate tests revealed: (a) a significant effect for the social comparison goal $\left(F_{1,170}=65.21, p<.01\right)$, with the adolescents having less social comparison goals in academic situations $\left(M_{\mathrm{z} \text { scores }}=-.67\right)$ than in sport situations $\left(M_{\mathrm{z} \text { scores }}=.40\right)$; and (b) a significant effect for the reward goal $\left(F_{1,170}=69.87, p<\right.$ $.0001)$, with the adolescents having less reward goals in sport situations $\left(M_{\mathrm{z} \text { scores }}=-.43\right)$ than in academic situations $\left(M_{\mathrm{z} \text { scores }}=.68\right)$.

\section{Discussion}

In the first place, we observed that sport is the most important social domain of achievement for our sample of French teenagers. They chose to situate their essays more within the framework of sport activities than in school or in other social domains such as leisure activities, music, or painting. Contrary to our hypothesis and previous literature about sport participation among French adolescents (7), no gender differences were found in our analysis. It might be hypothesized that the massive increase of girls/women in sport over the last 30 years has led to the fact that sport is no longer considered a domain of exclusively male achievement.

In contrast, our analysis of the data revealed a significant difference between the Maghrebian and the European adolescents. It confirms our hypothesis about ethnic origin differences in choices of social situations of achievement. The Maghrebian teenagers chose more academic situation than the European teenagers. No difference was found in the choice of sport situations. The choice of school situations, although perhaps surprising in light of the massive academic failure of teenagers in Maghreb, well reflects the "cult of the school" of North African immigrants (4). 
These results have to be interpreted in the light of the particular position of one of the groups composing our population. Indeed, the Maghrebian girls revealed particular choices. As reflected in Table 2, this group of subjects is the only one to write essays more often describing an academic situation than a sport situation or any other. We can hypothesize that this particular position is the consequence of a double influence. First, the traditional social position of women in Muslim societies accounts certainly for a great part of the influence. In most of these societies, the social relationships are characterized by the division between the "private space" (that of women) and the "public space" (that of men; 5); practicing sport or other cultural activities is supposed to be in the public space. It is not the traditional place of the Maghrebian girl, who must always be watched by a male member of the family. Second, in the immigrated Maghrebian family, young women are the central point of transition between the traditional patriarchal society and a new way of life. These young women are often in the grip of conflicts about values and roles (4). To resolve them, they often lean on scholastic success to achieve their desire for autonomy.

For our hypotheses concerning the gender and cultural differences in the choices of the achievement goals, results corresponded globally to our expectations. First, according to the hypotheses and to previous literature concerning gender differences in goal orientations (e.g., 19), the multivariate analyses revealed a significant difference between the two genders in their preferential goals. But contrary to what we expected, this difference concerned only the mastery goal. Although the differences between girls and boys in goal orientations went in the expected direction, none reached a significant level. Gill (19) underlined that gender differences in achievement cognitions may be influenced by the gender-linked nature of an activity. Therefore, masculine activities (like sport) could foster masculine goal orientations (i.e., low mastery/social and high social comparison/reward orientations), and feminine activities could foster feminine goal orientations (i.e., high mastery/social and low social comparison/reward orientations). From our results, we can suggest that sport and academic activities are no longer considered, in our society, as being exclusively masculine social domains, and thus resulting in more homogeneity in male and female goal orientations. Nevertheless, inside every domain (sport, school), some practices have different perceived gender characteristics for girls and boys. For example, dance is often perceived as a feminine activity, whereas rugby is perceived as more masculine. In the academic domain, the same distinctions can be made between various subjects (e.g., French, mathematics). The particular position of the Maghrebian boys in the sport domain (see Figure 1) is illustrative of this phenomenon. Their goal orientations are relatively different from the three others groups, which seem relatively homogeneous. One possible explanation is the importance accorded by this group on demonstrating masculine personal qualities in a social activity traditionally judged as masculine. Further research comparing achievement cognitions between particular sports and academic domains should be undertaken to test such an assumption.

Second, we can see a multivariate significant interaction effect between the social situation of achievement and the preferential goals pursued by the subjects. The univariate tests showed differences only between social comparison goals (sport $>$ academic) and reward goals (academic $>$ sport). Clearly, the nature of the social domain of achievement in which the adolescents are situated will influence whether they are likely to become intrinsically interested or if they will work (or practice) for extrinsic goals (such as grades, marks, money, medals) as their primary motivator. 


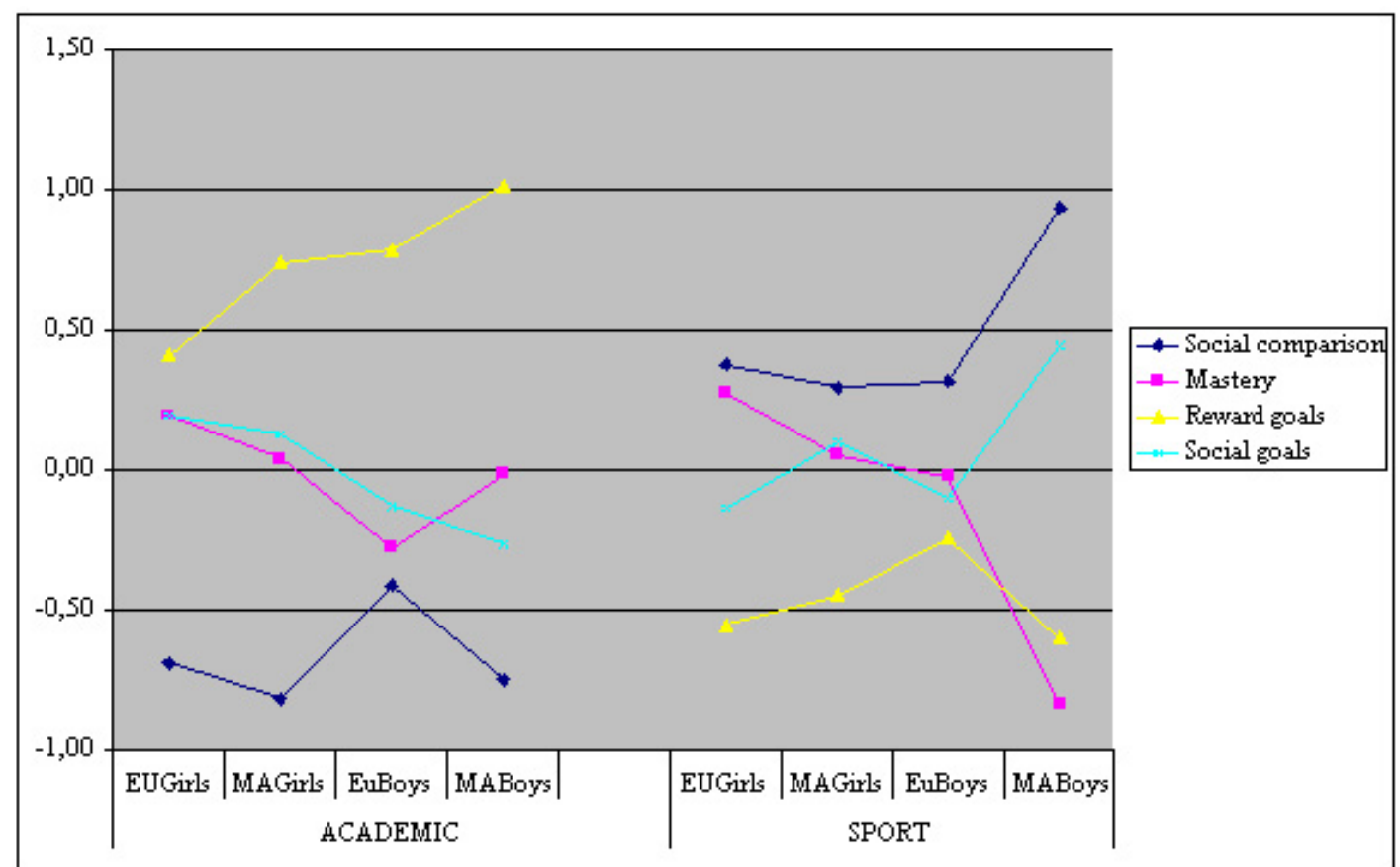

Figure 1 - Number of quotes (standardized) for every goals of achievement according to the gender and the ethnic origin of subjects.

Finally, it seems that the ethnic origin moderately influenced the goal orientations. We can advance several hypotheses to explain the absence of significant effect. First, the culture of the immigrated French Maghrebian is certainly very specific. This culture is not comparable to the traditional family from the Maghreb, or comparable to the dominant model in France, and it is characterized by the ambivalence between traditional domestic values and more modern values. Furthermore, the French cultural tendency of assimilation of the immigrated population is different from that of the Anglo-Saxon culture. This tendency is the result of a secular history which has also resulted in a logic of "gobbling up." One is easily accepted provided that he/she abandons all that differentiates him/her. Future research including an immigrant Maghrebian sample and a native Maghrebian sample will be necessary to verify this assumption.

This study has two principal limitations. First, the sample was limited to examining other achievement domains, like leisure activities and art (music, painting, theater), that were chosen by too few subjects. It would be interesting to examine additional domains. Second, the results of this study could be confounded because of a focus on ethnic origin instead of socio-economical status (see 28). Unfortunately, the limited access to information concerning the subjects' families (to guarantee anonymity) made consideration of this variable impossible. Future research should attempt to study the effects of the socio-economical status of the subjects.

In conclusion, the culture of the immigrated French Maghrebian is certainly very specific. This culture is not comparable to the traditional family from the Maghreb, or comparable to the dominant model in France, and it is characterized by the ambivalence between traditional domestic values and more modern values. Future research that includes an immigrant Maghrebian sample and a native Maghrebian sample is necessary to embrace all the complexity of intercultural differences between the populations of our study. 
References
1. Bardin L. 1977. Content analysis. Paris: PUF. (In French.)

2. Bond MH. 1988. Finding universal dimensions of individual variation in multicultural studies of values: the Rokeach and Chinese value surveys. Journal of Personality and Social Psychology 55:100915.

3. Bouamama S. 1993. From the bad adventure to the citizenship. Paris: Desclée de Brouwer. (In French.)

4. Bouamama S, Sad Saoud H. 1996. Maghrebian's family of France. Paris: Desclée de Brouwer. (In French.)

5. Bourdieu P. 1970. Sociology of Algeria. Paris: PUF. (In French.)

6. Chaulet C. 1971. The self-employed Mitidja. Alger: SNED. (In French.)

7. Davisse A, Louveau C. 1998. Sports, school, society. The gender difference. Paris: L'Harmattan. (In French.)

8. Duda JL. 1985. Goals and achievement orientations of Anglo and Mexican-American adolescent in sport and the classroom. International Journal of Intercultural Relations 9:131-55.

9. Duda JL. 1986. A cross-cultural analysis of achievement motivation in sport and the classroom. In: Vander Velden L, Humphrey J, editors. Current selected research in the psychology and sociology of sport. New York: AMS Press, p. 115-32.

10. Duda JL, Allison MT. 1989. The attributional theory of achievement motivation: cross-cultural considerations. International Journal of Intercultural Relations 13:273-86.

11. Duda JL, Allison MT. 1990. Cross-cultural analysis in exercise and sport psychology: a void in a field. Journal of Sport and Exercise Psychology 12:114-31.

12. Duda JL, Fox KR, Biddle SJH, Amstrong N. 1992. Children's achievement goals and beliefs about success in sport. British Journal of Educational Psychology 62:313-23.

13. Duda JL, Nicholls JG. 1992. Dimensions of achievement motivation in schoolwork and sport. Journal of Educational Psychology 84:290-99.

14. Duru-Bellat M. 1990. The girls' school. Which formation for which social roles? Paris: L'Harmattan. (In French.)

15. Duru-Bellat M. 1994. Girls and boys at school, sociological and psychosocial approaches. Part I: sexual school career, reflection of abilities differences or attitudes differences? Revue Française de Pédagogie 109:111-41.

16. Duru-Bellat M. 1995. Girls and boys at school, sociological and psychosocial approaches. Part II: the school construction of sex differences. Revue Française de Pédagogie 110:75-109.

17. Eccles JS. 1987. Gender roles and women's achievement-related decisions. Psychology of Women Quarterly 11:135-72.

18. Ghiglione R, Beauvois JL, Chabrol C, Trognon A. 1985. Handbook of content analysis. Paris: Armand Colin. (In French.)

19. Gill DL. 1992. Gender and sport behavior. In: Horn TS, editor. Advances in sport psychology. Champaign, IL: Human Kinetics, p. 143-60.

20. Lacoste-Dujardin C. 1992. Yasmina and the other of Nanterre and elsewhere, girl of Maghrebian parents in France. Paris: La Découverte. (In French.)

21. Maehr ML. 1974. Culture and achievement motivation. The American Psychologist 29:887-96. 
22. Maehr ML. 1984. Meaning and motivation. In: Ames R, Ames C, editors. Research on motivation in education: student motivation, 1. New York: Academic Press, p. 115-44.

23. Maehr ML, Braskamp LA. 1986. The motivation factor: a theory of personal investment, Lexington, MA: Lexington/D.C. Heath.

24. Maehr ML, Nicholls, JG. 1980. Culture and achievement motivation: a second look. In: Warren N, editor. Studies in cross-cultural psychology, 3. New York: Academic Press, p. 221-67.

25. McInerney DM. 1992. Cross-cultural insights into school motivation and decision making. Journal of Intercultural Studies 13:53-74.

26. Mucchielli R. 1988. The content analysis of documents and communications. Paris: ESF. (In French.)

27. Patton MQ. 1980. Qualitative evaluation methods. Beverly Hills, CA: Sage.

28. Phalet K, Clayes W. 1993. A comparative study of Turkish and Belgian youth. Journal of CrossCultural Psychology 24:319-343.

29. Roberts GC, Walker BW. in press. Achievement goal theory in sport and physical activity. In: Cury F, Sarrazin Ph, editors. Motivation and physical activity. Paris: PUF. (In French.)

30. Triandis HC. 1995. Motivation and achievement in collectivist and individualistic cultures. In: Maehr ML, Pintrich PR, editors. Advances in motivation and achievement: culture, motivation and achievement, 9. Londres, Greenwich: JAI Press. p. 1-30.

31. Triandis HC, Bontempo R, Villareal M. 1988. Individualism and collectivism: cross-cultural perspectives on self-ingroup relationships. Journal of Personality and Social Psychology 54:323-38.

32. Wankel LM, Kreisel PSJ. 1985. Methodological consideration in youth sport motivation research: a comparison of open-ended and paired comparison approaches. Journal of Sport Psychology 7:65-74.

33. Wentzel KR. 2000. What is it I'm trying to achieve? Classroom goals from a content perspective. Contemporary Educational Psychology 25:105-15.

\section{Notes}

${ }^{1}$ See Wankel and Kreisel (32) for an example and more information about the comparison of quantitative and qualitative methods of investigation in motivation research.

${ }^{2}$ In France, the end of the first part of the secondary school career (around 15-16 years old) is ended by a special exam called "Brevet des Collèges." During this exam, the pupils pass different tests: French, mathematics, history, etc. After correction of the exam, a special permission by the Versailles' district inspection of the French Ministry of Education allowed us to gain entry to limited information concerning the adolescents (gender, place of birth, parents' nationality and place of birth, parents' employment occupation).

${ }^{3}$ Subject 2 was a subject of reflection concerning the importance to be granted to one's work in life.

${ }^{4}$ The $N$ index correspond to the following formula: $N=(c \times 2) /(a+b)$, where $a$ is the number of specific quotes of the first researcher, $b$ is the number of specific quotes of the second researcher, and $c$ is the number of common quotes between the two analyses. When $N$ is $>.70$, the homogeneity of the coding is considered acceptable (18).

${ }^{5}$ Unfortunately, we cannot realize a chi-square test with the four groups of adolescents (i.e., Maghrebian girls, Maghrebian boys, European girls, European boys) because there were too few Maghrebians (boys and girls) that chose other domains for achievement situation (see Table 2). 
${ }^{6}$ As there was a very limited number of adolescents (specially Maghrebian) who chose other domains as social situation of achievement, the MANOVA design was not possible. Therefore, it was not taken into account for the second part of this study.

\section{Acknowledgments}

We thank Mme Cuaz-Perolin, Principal of the College Debussy (Saint Germain-en-Laye) for her assistance with the Versailles' district assessment, which enabled us to achieve this work.

\section{About the Authors}

P. Fontayne < paul.fontayne@staps.u-psud.fr $>$ and J-P. Famose $<$ jean-pierre.famose@staps.upsud.fr $>$ are with the Centre de Recherches en Sciences du Sport at the University of Paris XIOrsay, France. Philippe Sarrazin <philippe.sarrazin@ujf-grenoble.fr> is with the Laboratoire d'Études et de Recherches sur l'Offre Sportive at the University of Grenoble I, France.

Paul Fontayne is Assistant Professor at the University of Paris-Sud Orsay, France. His principal domain of research is the influence of the socio-cultural (e.g., gender, ethnicity) context on achievement motivation in sport.

Philippe Sarrazin is Assistant Professor at the University of Grenoble I, France. He has authored numerous articles concerning the goals of achievement in sport, especially the link between achievement motivation and sport dropout.

Jean-Pierre Famose is Professor at the University of Paris-Sud Orsay, France. He has been working for many years on achievement motivation in sport. His research mainly concerns the physical self-concept and its relation with the determinants of self-confidence. 